\title{
Editorial
}

\section{Day one}

Journal of Brand Management (2010) 17, 241-242. doi:10.1057/bm.2009.38

The Journal of Brand Management, possibly uniquely, spans the worlds of academic and professional practice in branding. I've just started to do that too. In the past 10 weeks, I've begun teaching on the new Brand Leadership MSc at the University of East Anglia in Norwich, UK, while continuing to advise clients at Wolff Olins, the brand consultancy in London. Monday is teaching: the rest of the week is practice. For me, Monday, 21 September was day one of this new way of working.

What's struck me already is that there's so much for each world to learn from the other. For example, at Wolff Olins, we're just starting to explore the idea that brands are made by consumers, not corporations, and that old models of brand as a form of corporate control no longer work. This is new and slightly scary for us and our clients, but it's a topic talked about for years by academics - As Heding, Knudtzen and Bjerva show in their useful new survey Brand Management (Routledge, 2009). We urgently need to transplant those theory insights into our professional practice.

At the same time, we're finding that our professional practice is changing. Clients are increasingly asking us not to redesign their logos, but to help them innovate. In a recent project with Mercedes-Benz, for instance, we used its brand idea to inspire three new businesses. Clients know that customers these days believe not image but reality - so the business of branding is increasingly about changing reality, which means innovation. But we can't find any academic work yet on this new art of brand-led innovation: researchers urgently need to transplant our practice into theoretical frameworks.

And not only is there a gulf between the two worlds, there are also yawning chasms within them. Within the world of practice, there's a wide gap between an advertising agency view (big ideas to sell products) and a brand consultancy view (big ideas to give organisations an identity). Within the world of theory, there's an equally broad divide between marketing academics and organisational development academics. We've all adopted the vocabulary of brand to suit our own particular interests - and, in doing so, we've given the critical words our own meanings. Brand, identity, proposition, positioning: none has a fixed definition. All of which means that we often think we're agreeing with each other, when in reality we're not.

This was underlined for me at a recent UK government conference, Branding in the modern economy, organised by the Intellectual Property Office on 11 November. David Lammy, the minister for higher education and intellectual property, wants the government for the first time to take an interest in, and maybe even have a policy on, branding: and this was day one for this new idea. Academics, lawyers, civil servants, brand owners like Innocent, advertising agencies like Bartle Bogle Hegarty (BBH) and brand consultants like Interbrand, all gathered for a day, and there was much vigorous agreement. There now seems to be consensus, for instance, that brand is not a marketing gadget, but an operating 
principle for organisations. But there were many hidden cracks in the conversation, and a definite sense that most people outside the conference don't yet see brand in this holistic way.

The truth that struck me that day, and keeps hitting me on my teaching Mondays, is that we're actually all one profession. We are the profession that gives cultural meaning to organisations, services, products, even whole countries. We therefore play an invaluable role in society. But we're a profession is its infancy. A profession that needs to define its terms. A profession that needs much more rigour. A profession whose practice should be guided by grounded theory, not just by market research. A profession whose theory needs to be in tune with the latest practice. A profession that needs clear ethics, to counter critics like
Naomi Klein, and proper professional education. But also a profession like architecture, say, that depends on creativity, that can't be squashed into processes and frameworks and standards. Branding is maybe the newest profession, but it's a paradoxical one.

Though many of us have been working away at branding for 20 years or more, we're only at the start - day one - of this profession. We need now to shape it in a properly global way, avoiding the temptation to be western-centric, and with our eyes on the future of branding, not its past. This journal has a vital role to play as incubator.

Robert Jones Editorial Board E-mail: robert.jones@wolffolins.com 